\title{
Bmf upregulation through the AMP-activated protein kinase pathway may protect the brain from seizure-induced cell death
}

\author{
C Moran ${ }^{1,2,4}$, A Sanz-Rodriguez ${ }^{1,3,4}$, A Jimenez-Pacheco ${ }^{1,3}$, J Martinez-Villareal ${ }^{1,3}$, RC McKiernan ${ }^{1,3}$, EM Jimenez-Mateos ${ }^{1,3}$, \\ C Mooney ${ }^{1,3}$, I Woods ${ }^{1}$, JHM Prehn ${ }^{1,3}$, DC Henshall ${ }^{1,3}$ and T Engel ${ }^{*, 1,3}$
}

Prolonged seizures (status epilepticus, SE) can cause neuronal death within brain regions such as the hippocampus. This may contribute to impairments in cognitive functioning and trigger or exacerbate epilepsy. Seizure-induced neuronal death is mediated, at least in part, by apoptosis-associated signaling pathways. Indeed, mice lacking certain members of the potently proapoptotic BH3-only subfamily of Bcl-2 proteins are protected against hippocampal damage caused by status epilepticus. The recently identified $\mathrm{BH} 3$-only protein $\mathrm{Bcl}-2$-modifying factor $(\mathrm{Bmf})$ normally interacts with the cytoskeleton, but upon certain cellular stresses, such as loss of extracellular matrix adhesion or energy crisis, Bmf relocalizes to mitochondria, where it can promote Bax activation and mitochondrial dysfunction. Although Bmf has been widely reported in the hematopoietic system to exert a proapoptotic effect, no studies have been undertaken in models of neurological disorders. To examine whether Bmf is important for seizure-induced neuronal death, we studied Bmf induction after prolonged seizures induced by intra-amygdala kainic acid (KA) in mice, and examined the effect of Bmf-deficiency on seizures and damage caused by SE. Seizures triggered an early (1-8h) transcriptional activation and accumulation of Bax in the cell death-susceptible hippocampal CA3 subfield. Bmf mRNA was biphasically upregulated beginning at $1 \mathrm{~h}$ after SE and returning to normal by $8 \mathrm{~h}$, while again being found elevated in the hippocampus of epileptic mice. Bmf upregulation was prevented by Compound $\mathrm{C}$, an inhibitor of adenosine monophosphate-activated protein kinase, indicating Bmf expression may be induced in response to bioenergetic stress. Bmf-deficient mice showed normal sensitivity to the convulsant effects of KA, but, surprisingly, displayed significantly more neuronal death in the hippocampal CA1 and CA3 subfields after SE. These are the first studies investigating Bmf in a model of neurologic injury, and suggest that Bmf may protect neurons against seizure-induced neuronal death in vivo.

Cell Death and Disease (2013) 4, e606; doi:10.1038/cddis.2013.136; published online 25 April 2013

Subject Category: Neuroscience

Temporal lobe epilepsy (TLE) is the most common and most drug-refractory form of epilepsy in adults. TLE is often associated with selective neuron loss and gliosis in the hippocampus of patients, which may be both the cause and consequence of recurrent seizures. ${ }^{1,2}$ Recurring seizures may contribute to progressive damage and underlie cognitive impairments, particularly in memory function. Therefore, preventing hippocampal sclerosis or ongoing seizure-induced neuronal death is a potential therapeutic strategy for mitigation or prevention of epilepsy. ${ }^{3,4}$ Apoptosis, or programmed cell death, has been shown to be responsible for a significant component of seizure-induced neuronal loss in different animal models of status epilepticus (SE), and these pathways are also regulated in human TLE. ${ }^{3}$

The Bcl-2 family of proteins are critical for the intrinsic mitochondrial apoptotic pathway and are characterized by shared structural motives, called $\mathrm{Bcl}-2$ homology (BH) domains. They comprise anti- and pro-apoptotic members that function co-ordinately to control caspase-dependent and -independent cell death. ${ }^{5}$ The proapoptotic members of the family fall into two categories. The first are the multidomain Bax-like molecules such as Bax and Bak, which share $\mathrm{BH}$ 1-3 regions. Activated Bax and/or Bak promote mitochondrial permeability, allowing the release of apoptogenic factors such as cytochrome $\mathrm{c}$, which then promotes activation of the caspase cascade and cell death. The second group are the $\mathrm{BH} 3-$ only proteins, which share only the single $\mathrm{BH} 3$ domain in common. BH3-only proteins operate by binding to Bcl-2-like prosurvival proteins to initiate apoptosis by antagonizing their function, or possibly by directly activating Bax-like multidomain proteins. ${ }^{5,6}$ Members of the $\mathrm{BH} 3$-only proteins can be regulated through their transcriptional expression and by

\footnotetext{
${ }^{1}$ Department of Physiology and Medical Physics, Royal College of Surgeons in Ireland, Dublin, Ireland; ${ }^{2}$ National Centre for Neurosurgery, Beaumont Hospital, Dublin, Ireland and ${ }^{3}$ Centre for the Study of Neurological Disorders, Royal College of Surgeons in Ireland, Dublin, Ireland

${ }^{*}$ Corresponding author: T Engel, Department of Physiology and Medical Physics, Royal College of Surgeons in Ireland, 123 St. Stephen's Green, Dublin 2, Ireland. Tel: + 35314028630; Fax: + 35314022447; E-mail: tengel@ rcsi.ie

${ }^{4}$ These authors contributed equally to this work.

Keywords: temporal lobe epilepsy; BH3-only proteins; apoptosis; neurons; status epilepticus

Abbreviations: Bmf, Bcl-2-modifying factor; AMPK, adenosine monophosphate-activated protein kinase; CA, cornu ammonis; EEG, electroencephalogram; FJB, Fluoro-Jade B; i.c.v., intracerebroventricular; HAHFDs, high-amplitude high-frequency discharges; JNK, c-Jun NH(2)-terminal kinase; KA, kainic acid; RT-qPCR, real-time quantitative polymerase chain reaction; SE, status epilepticus

Received 28.8.12; revised 8.2.13; accepted 11.3.13; Edited by A Verkhratsky.
} 
post-translational modifications. ${ }^{6,7}$ Recent studies using knockout models of different $\mathrm{BH}$-only proteins have shown that the loss of some of these proapoptotic proteins can not only provide substantial neuroprotection after SE, but that this neuroprotection can also translate into a milder emergent

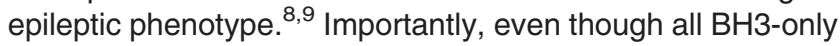
proteins studied to date become activated during SE, their contribution to cell death differs from one member to the other. $^{3}$

The recently identified protein $\mathrm{Bmf}$ (Bcl-2-modifying factor) is a member of the BH3-only subgroup. ${ }^{10}$ It is found expressed in the hematopoietic system with highest levels in immature $T$ and $\mathrm{B}$ cells, as well as in mammary glands. ${ }^{11}$ The $b m f$ gene encodes for a $21 \mathrm{kDa}$ protein $^{10}$ with various splice variants reported. ${ }^{12,13}$ Under normal conditions in the cell, Bmf is sequestered to the actin cytoskeleton-based myosin $\mathrm{V}$ motor complex through its interaction with dynein light chain $2 .{ }^{10}$ In response to stress stimuli such as detachment of adherent cells from their substratum (anoikis) or exposure to actin depolymerization drugs, Bmf is released to promote apoptosis. ${ }^{10}$ The signals that trigger the release of Bmf remain illdefined, but phosphorylation of Bmf within the DLC interaction motif has been proposed as a possible mechanism. ${ }^{11}$ Transcriptional upregulation of $\mathrm{Bmf}$ has been reported to be induced by transforming growth factor beta-mediated signals, ${ }^{14}$ adenosine monophosphate-activated protein kinase (AMPK) activation, ${ }^{15}$ histone deacetylase inhibitor treatment, ${ }^{16}$ C-Jun $\mathrm{NH}(2)$-terminal kinase (JNK) phosphorylation ${ }^{17}$ and cell stressors that repress CAP-dependent protein synthesis. ${ }^{13}$ Transcriptional repression has been reported through the Erk and Akt pathway. ${ }^{18}$ Compared with Bim, the closest related BH3-only protein, Bmf shows only limited proapoptotic potential, binding selectively to $\mathrm{Bcl}-2, \mathrm{Bcl}-\mathrm{xl}$ and $\mathrm{Bcl}-\mathrm{w}$, and to a lesser extent to $\mathrm{Mcl}-1 .{ }^{11}$ Direct activation of Bax has been observed for different BH3-only protein members, such as Bid and Bim, ${ }^{19}$ and more recently, although described as a weaker activator, studies suggest Bmf might be capable of also directly activating Bax/Bak. ${ }^{20} \mathrm{Bmf}$ seems to be dispensable for normal embryonic development and organogenesis. ${ }^{21} \mathrm{Bmf}$ knockdown has been shown to provide substantial protection against different cell stressors, such as glucocorticoids and $\gamma$ irradiation, ${ }^{21}$ histone deacetylase inhibition, ${ }^{16}$ certain types of anoikis in epithelial cells, ${ }^{18,21,22}$ arsenic trioxide-induced cell death ${ }^{23}$ and apoptosis of beta and renal proximal tubular cells in diabetes. ${ }^{15,24}$ Studies in different cell types from bmf-deficient mice suggested, however, redundancy with other $\mathrm{BH} 3-$ only proteins during the processes of apoptosis. ${ }^{25,26}$

A functional role for $\mathrm{Bmf}$ in diseases of the nervous system has not yet been explored. Here, we investigated the role of Bmf in a mouse seizure model, and assessed seizure-induced neuronal death in bmf-deficient mice.

\section{Results}

Bmf is induced after SE. To investigate the role of the $\mathrm{BH} 3-$ only protein Bmf in seizure-induced cell death, we triggered SE in mice via the well-characterized method of intra-amygdala microinjection of kainic acid (KA). ${ }^{27}$ Mice typically showed first electrographic seizure bursts on electroencephalogram (EEG) shortly after microinjection of $K A$ into the basolateral amygdala. No seizure activity was observed in vehicle-treated mice. Mice displayed typical behavioral changes during SE, including initial immobility, tail extension (Straub-tail) and continuing to clonus, head bobbing and rearing and falling and occasionally tonic-clonic seizures with the loss of posture and jumping. Mice received systemic lorazepam $40 \mathrm{~min}$ after KA injection to curtail seizures, and to reduce morbidity and mortality. As reported before, ${ }^{28}$ analysis of hippocampal pathology $72 \mathrm{~h}$ after SE showed cell death was mainly restricted to the ipsilateral CA3 hippocampal subfield shown with the neuronal cell death marker FJB (Figures 1a and b). No cell death was observed in control vehicle-injected animals or in the contralateral hippocampus of mice subjected to SE (Figure $1 \mathrm{~b}$ and data not shown).

To confirm SE activates the intrinsic mitochondrial apoptotic pathway, we initially studied Bax. Bax mRNA was significantly increased in the ipsilateral cell death-susceptible CA3 subfield, but decreased in the less damaged ipsilateral CA1 and dentate gyrus subfields after SE (Figure 1c and Supplementary Figures 1a and b). Total Bax protein levels were also increased in the ipsilateral CA3 subfield (Figure 1d). Immunohistochemistry was next used to visualize where in the hippocampus Bax was activated. Active Bax immunoreactivity, detected with the epitope-specific anti-Bax 6A7 antibody, was mainly localized in the CA3 subfield of the hippocampus and appeared as a perinuclear, often punctate stain consistent with mitochondrial localization (Figure 1e). No active Bax immunoreactivity was detected in the seizuredamaged CA3 subfield of bax-deficient mice (Figure 1e). A causal role of Bax was not pursued in the present study because $\mathrm{Bax}^{-/-}$mice displayed grossly enlarged brain volume and brain weight when compared with wt littermates (Supplementary Figures $1 \mathrm{c}$ and $\mathrm{d}$ ).

$B m f$ expression was increased 1 and $4 \mathrm{~h}$ after SE and returned to baseline at later time-points (Figure 1f). Two commercially available Bmf antibodies tested failed to reliably detect Bmf protein in the brain tissue, as previously reported. ${ }^{18,29}$

Bmf induction in epileptic mice. As reported previously, ${ }^{28}$ intermittent video and EEG monitoring of mice detected the first spontaneous (i.e. epileptic) seizures $3-5$ days after SE (Figures $2 \mathrm{a}$ and $\mathrm{b}$ ). During continuous epilepsy monitoring 2 weeks after SE, mice experienced an average $3.5 \pm 5.5$ seizures per day with an average behavior (Racine scalebased) score of $3.4 \pm 0.8(n=6)$. All mice experienced at least one seizure event during 3 days of recording, consistent with previously reported data. ${ }^{28,30}$ In tissue sections from epileptic mice 14 days after SE, the hippocampus displayed a visible lesion within the ipsilateral CA3 subfield comprising neuron loss and astrogliosis (Figure 2c). The contralateral hippocampus appeared grossly normal, without any visible changes in cell density or gliosis (data not shown). To determine whether there was any ongoing cell death in these chronically epileptic mice, FJB staining was performed. No FJB-positive cells were detected in the CA3 region of the ipsilateral hippocampus of epileptic mice 14 days after SE (Figure 2d). Interestingly, despite no apparent ongoing 
a

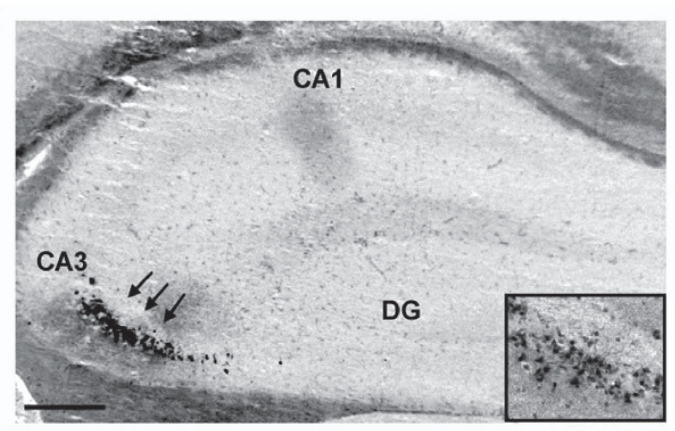

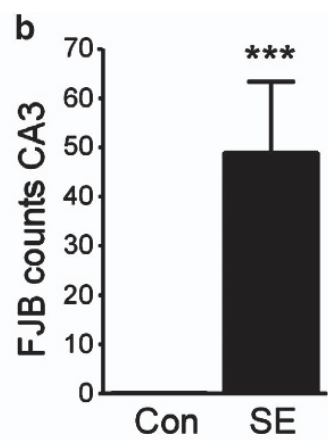

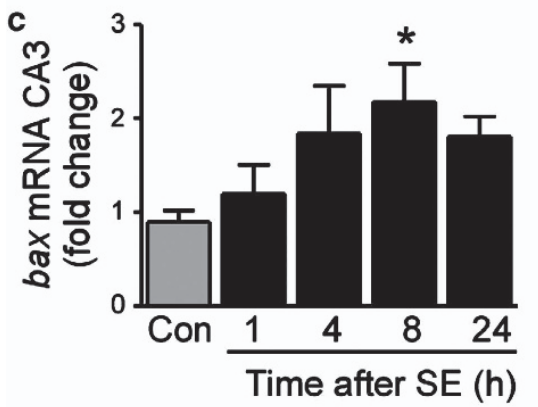

d

Time after SE (h)

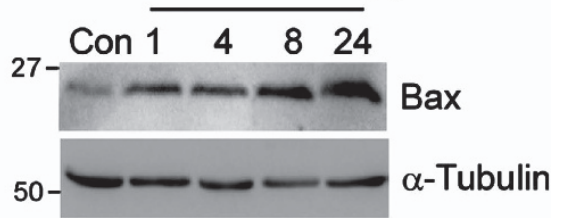

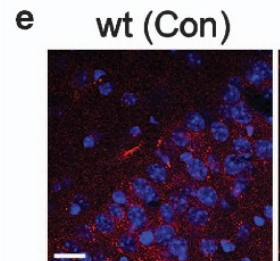

wt (SE)

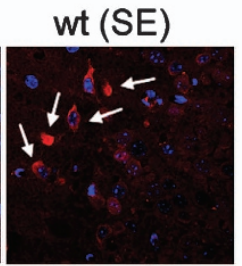

$\mathrm{Bax}^{-1-}(\mathrm{SE})$

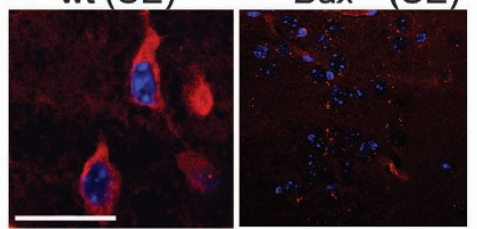

f

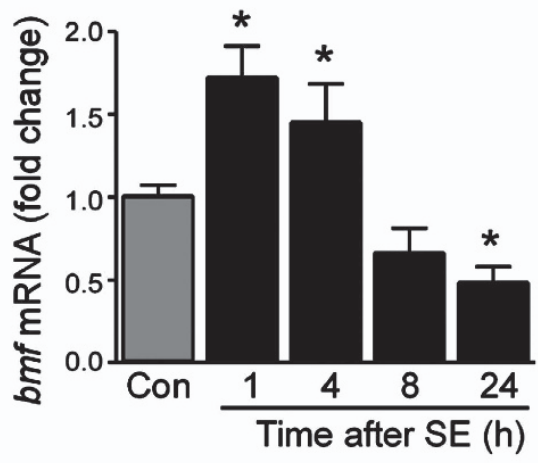

Figure 1 Bmf induction after SE. (a) Representative photomicrograph of a coronal brain section at the level of the dorsal ipsilateral hippocampus $72 \mathrm{~h}$ after SE showing FJB-positive cells mainly in the CA3 subfield (arrows), whereas CA1 and dentate gyrus (DG) are mainly spared from cell death. (b) Average number of FJB-positive cells at a single level of the dorsal ipsilateral CA3 hippocampal subfield $72 \mathrm{~h}$ after SE $\left(n=5\right.$ per group; $\left.{ }^{* \star *} P<0.001\right)$. No cell death was observed in control (Con) non-seizure mice. (c) Graph showing increased bax mRNA in cell death-susceptible ipsilateral CA3, $8 \mathrm{~h}$ after $\mathrm{SE}\left(n=4\right.$ per group; $\left.{ }^{*} P<0.05\right)$ when compared with ipsilateral CA3 from control (Con) mice. (d) Representative western blots ( $n=1$ per lane) of cell lysates from ipsilateral CA3 subfield showing increased levels of Bax after SE when compared with ipsilateral CA3 from control (Con) mice. $\alpha$-Tubulin is shown as a loading control. (e) Confocal immunofluorescence photomicrographs showing cells positive for active Bax $8 \mathrm{~h}$ after SE in the CA3 region of the hippocampus. Note, no specific staining was present in the CA3 subfield of bax-deficient mice $8 \mathrm{~h}$ after SE (bottom right panel) and in control (Con) wt mice. (f) Graph showing increased bmf mRNA levels after SE ( $n=7$ (vehicle, control (Con)) and 5 (mice after SE)) when compared with control mice. CA $=$ cornus ammonis. Scale bar, $250 \mu \mathrm{m}$ (a) and $50 \mu \mathrm{m}$ (e)

neurodegeneration in epileptic mice, bmf mRNA was increased 14 days after SE in ipsilateral hippocampal tissue (Figure 2e).

Bmf induction through AMPK after SE. We next investigated potential pathways regulating Bmf expression after SE. Bmf has been shown to be induced by different kinases, including $\mathrm{JNK}^{17}$ and AMPK. ${ }^{15}$ We previously showed JNK pathway induction in the present model. ${ }^{9}$ Whether AMPK is induced in our model is unknown. To explore this, we immunoblotted with antibodies against phosphorylated AMPK, which is a read-out of increased AMPK function. ${ }^{31}$
AMPK phosphorylation increased shortly after SE in mice (Figures $3 a$ and b). To test whether specific inhibitors for these pathways repress bmf expression after SE, mice were given an intracerebroventricular (i.c.v.) injection of either SP600125 $(25 \mu \mathrm{M})$ (reversible inhibitor of JNK) or Compound $\mathrm{C}(1 \mathrm{mM})$ (reversible inhibitor of AMPK) before intra-amygdala KA injection. All vehicle-, SP600125- and Compound C- treated mice developed SE after KA injection, and seizure durations recorded by surface EEG were not significantly different between groups (data not shown and Figures $3 c$ and d). Cortical EEG recordings are an accurate indicator of intra-hippocampal seizure activity in this model. ${ }^{9}$ 


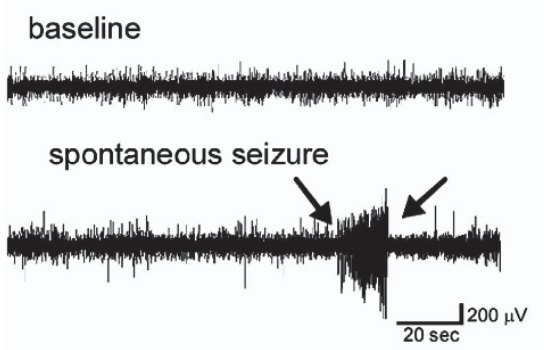

b

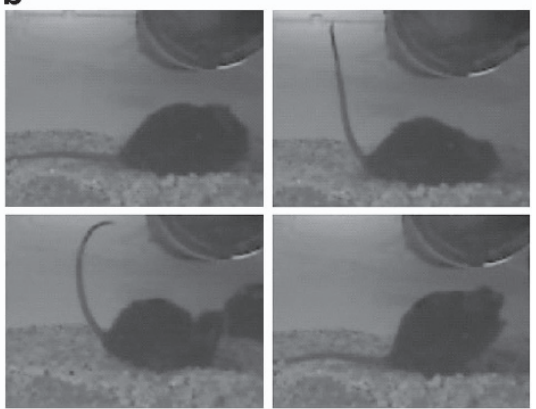

d

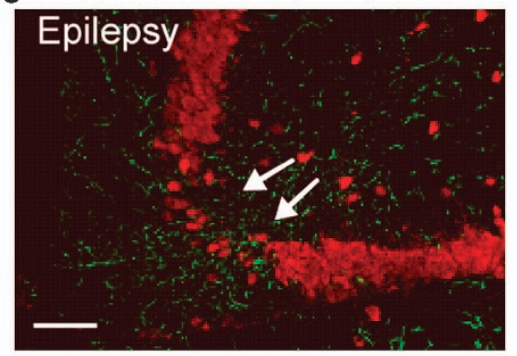

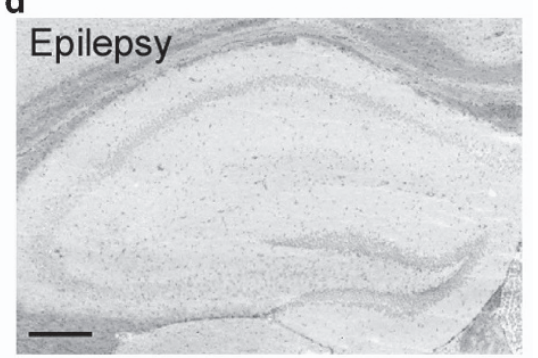

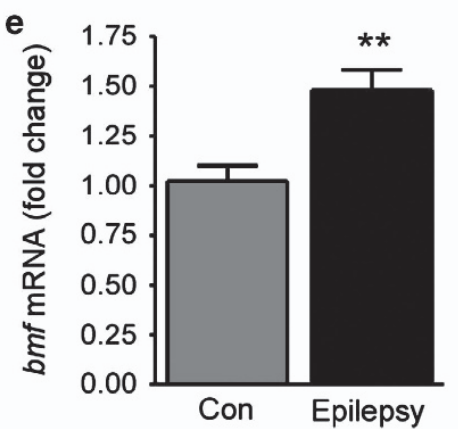

Figure 2 Bmf induction in mice with epilepsy. (a) Representative EEG recording of a spontaneous seizure and, (b) video stills showing typical tonic-clonic behavior during an epileptic seizure detected 14 days after SE. (c) Representative photomicrographs showing reactive astrocytes (GFAP, green) and loss of NeuN-positive neurons (red) in the ipsilateral CA3 subfield in epileptic mice 14 days after SE. Note, decreased neuronal density in ipsilateral CA3 (white arrows). (d) Representative photomicrograph of FJBstained coronal brain section at the level of the dorsal ipsilateral hippocampus of an epileptic mouse 14 days after SE. No ongoing neurodegeneration is present. (e) Graph showing increased bmf mRNA levels in epileptic mice 14 days post SE when compared with control (Con) mice ( $n=8$ (Con) and 5 ( 14 days post SE). ${ }^{* \star} P<0.01$ compared with control. Scale bar, $100 \mu \mathrm{m}(\mathbf{c})$ and $250 \mu \mathrm{m}$ (d)

Analysis of EEG included standard measures of seizure activity, such as scoring of high-amplitude high-frequency discharges (HAHFDs) and automated analysis of EEG power. ${ }^{30,32}$ As before, bmf mRNA was significantly upregulated after SE in vehicle-injected mice when compared with non-seizure control mice (Figure 3e). In contrast, bmf mRNA was not increased in mice pretreated with the specific AMPK inhibitor Compound C (Figure 3e). No differences in hippocampal bmf mRNA levels were found between non$\mathrm{KA}$ vehicle- and Compound $\mathrm{C}$-injected control mice (data not shown). No difference in bmf upregulation was found between seizure-vehicle mice and mice treated with the specific JNK inhibitor (data not shown). These results suggest that bmf mRNA is induced after SE at least in part by the cell stress sensor AMPK.

We also examined cell death in mice treated with Compound C compared with vehicle-injected seizure controls. Mice pretreated with the specific AMPK inhibitor
Compound $\mathrm{C}$ displayed increased seizure-induced cell death compared with vehicle-injected SE mice (Figures $3 f$ and g). We note that hippocampal damage levels in vehicle-injected mice in this part of the study are slightly lower than in the normal model, perhaps due to effects of vehicle (DMSO) on neuronal death. ${ }^{33}$

Hippocampal morphology, glutamate receptor expression and response to $\mathrm{KA}$ in Bmf-deficient mice. To determine whether Bmf is required for seizure-induced neuronal death in the hippocampus, we compared wild-type $\left(B m f^{+/+}\right)$and Bmf-deficient $\left(B m f^{-/-}\right)$mice in this model. To examine whether $B m f^{-/-}$mice display any developmental abnormalities that might render them more or less prone to seizures or hippocampal damage, we examined neuron numbers and KA receptor expression in the hippocampus. No gross hippocampal abnormalities were present in $\mathrm{Bmf}^{-/-}$mouse brains (Figures $4 \mathrm{a}$ and b) and 

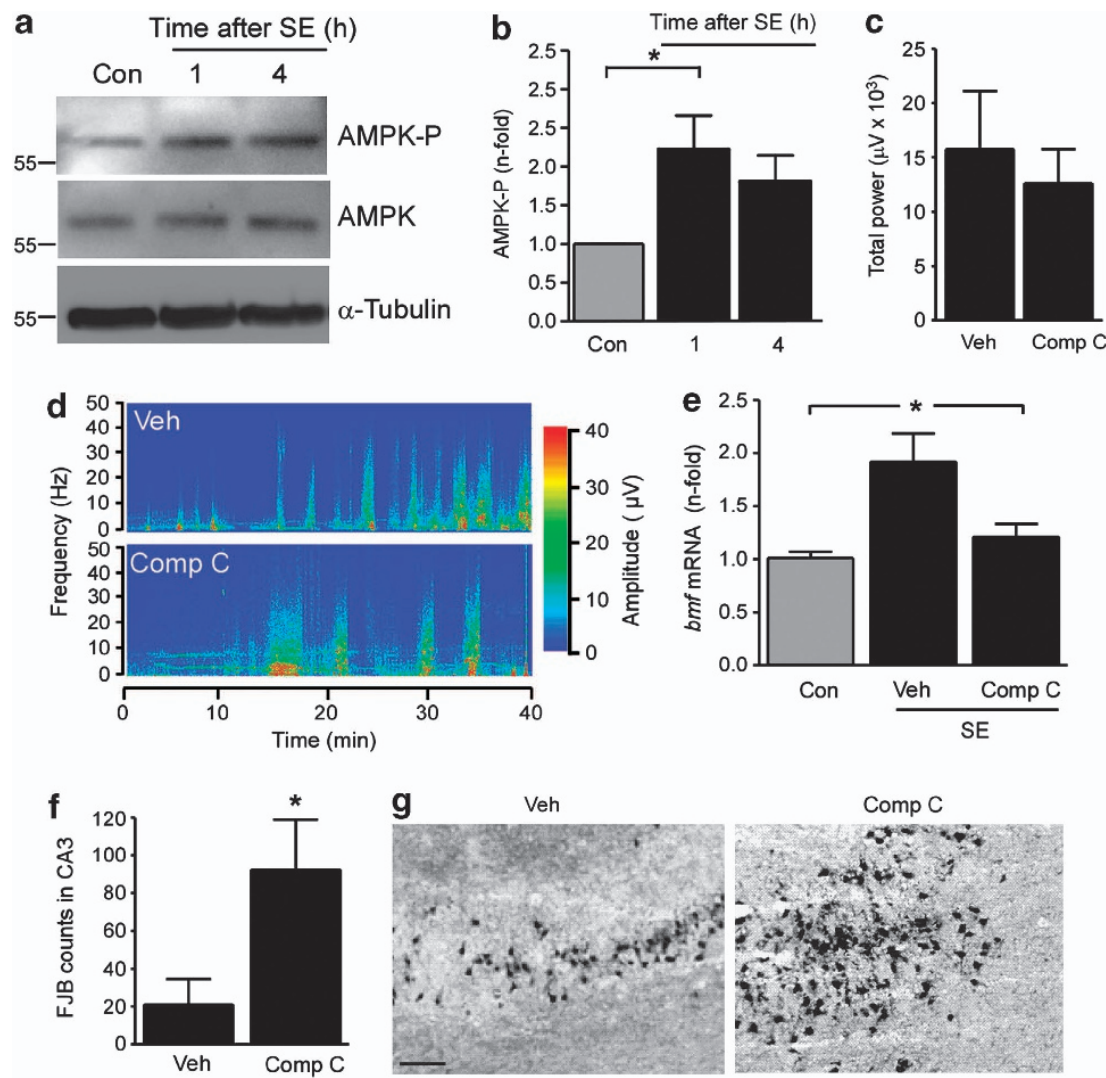

Figure 3 Upregulation of bmf after SE is blocked by AMPK inhibition. (a) Representative western blots ( $n=1$ per lane) showing increased AMPK phosphorylation (AMPK-P) $1 \mathrm{~h}$ after SE. No changes in total AMPK levels after SE were found. $\alpha$-Tubulin is shown as a loading control. (b) Graph showing increased AMPK phosphorylation $1 \mathrm{~h}$ after $\mathrm{SE}(n=4$ per group). (c) Graphs showing similar total seizure power during 40 min recoding period of cortical EEG starting after KA injection until injection of lorazepam in mice injected with Compound C (Comp C) compared with vehicle-injected (Veh) mice. (d) Representative seizure spectrogram showing amplitude and frequency during SE in mice treated with vehicle and Comp C. (e) Graph showing increased bmf mRNA levels $4 \mathrm{~h}$ after SE in vehicle-treated mice when compared with non-seizure control (Con) mice, whereas no bmfmRNA increase was found in SE mice pretreated with the AMPK inhibitor Comp C ( $n=7$ (Con) and 4 (Comp C)). (f) Graph showing increased cell death in Comp C-treated mice when compared with vehicle-injected mice $24 \mathrm{~h}$ after SE ( $n=5$ per group). (g) Representative photomicrographs of the CA3 subfield $24 \mathrm{~h}$ after SE of vehicle- and Comp C-treated mice. Scale bar in $\mathbf{g}, 50 \mu \mathrm{m} ;{ }^{*} P<0.05$ when compared with control

counts of NeuN-stained hippocampal subfields from $\mathrm{Bmf}^{+/+}$and $\mathrm{Bmf}{ }^{-/-}$mice revealed similar numbers of neurons in the CA1 and CA3 hippocampal subfield (Figures $4 a$ and $b$ ). Western blotting revealed no difference between genotypes for protein levels of the KA receptors GluR6/7 and $\mathrm{KA} 2$ (Figures $4 \mathrm{c}$ and $\mathrm{d}$ and data not shown). As expected, no expression of $b m f$ mRNA was detected in $\mathrm{Bmf}^{-/-}$mice (Figure 4e).

To establish whether or not Bmf ${ }^{-/-}$mice underwent an episode of SE equivalent to wt mice, animals from both groups were equipped with skull-mounted electrodes, and we recorded and quantified EEG between the time of KA microinjection and administration of lorazepam. No difference was found between $\mathrm{Bmf}^{+/+}$and $\mathrm{Bmf}^{-/-}$mice in total seizure time, total seizure power, amplitude and frequency (Figures $4 \mathrm{f}-\mathrm{j})$. Behavioral analysis confirmed EEG recordings showing no differences between $\mathrm{Bmf}^{+/+}$and $\mathrm{Bmf}^{-/-}$mice during first 40 min after KA injection using a modified Racine scale for mice. All mice injected with KA developed SE with no differences in severity between genotypes $(n=5$ per group; $P=0.91)$. To ensure that seizure cessation was the same between genotypes, EEG was recorded for an additional hour after lorazepam administration. No difference could be observed in seizure total power between genotypes in post lorazepam monitored EEG (Figures 4k and I).

Moreover, no difference between genotypes was observed in the expression of the activity-regulated cytoskeletonassociated protein $(A r c)$, an immediate early gene whose expression is a marker of increased neuronal activity ${ }^{34}$ (data not shown). To rule out any compensatory effects of other BH3-only proteins on SE-induced cell death in Bmf ${ }^{-1-}$ mice, real-time qPCR was performed for bim and puma, both of which have been implicated in seizure-induced cell death before. $^{8,9}$ No significant difference in the expresssion of bim and puma mRNA was found after SE between $\mathrm{Bmf}{ }^{+/+}$ and $\mathrm{Bmf}^{-/-}$mice (data not shown).

Increased vulnerability to seizure-induced neuronal death in Bmf-deficient mice. Last, we examined the histopathological consequences of $\mathrm{SE}$ in $\mathrm{Bmf}^{-/-}$mice. To assess hippocampal damage, FJB staining was performed $72 \mathrm{~h}$ after SE. As expected, $\mathrm{Bmf}^{+/+}$mice displayed damage that was mainly located in the ipsilateral CA3 subfield of the hippocampus, with almost no cell death 

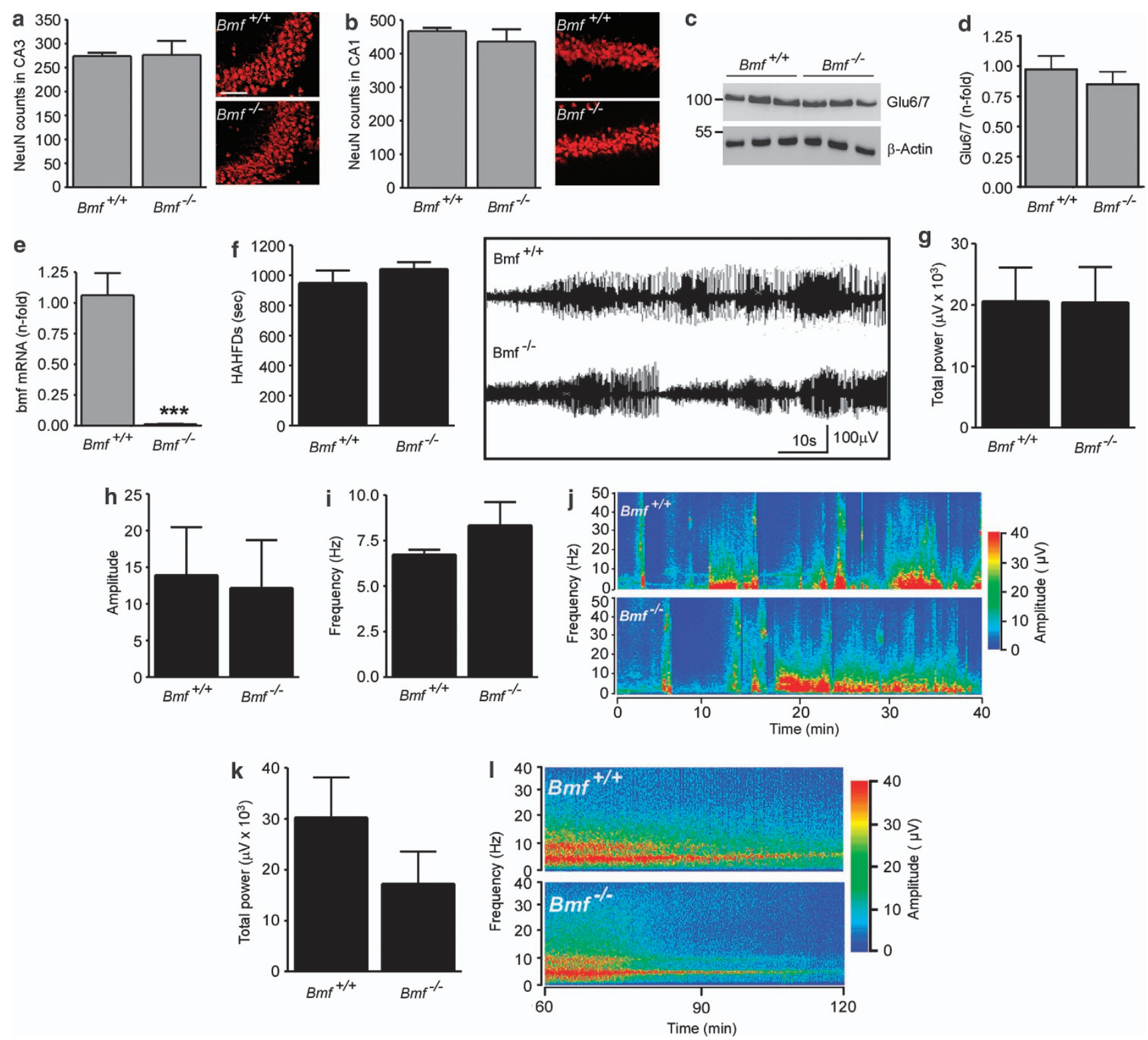

Figure 4 Normal hippocampal morphology and response to intra-amygdala KA in $\mathrm{Bmf}^{-1-}$ mice. Graph and representative photomicrographs showing similar numbers of NeuN-positive cells in the CA3 (a) and CA1 (b) subfield of $B m f^{+/+}$and Bmf ${ }^{-/-}$mice ( $n=3$ per group). (c) Representative western blot $(n=1$ per lane) and corresponding graph (d) showing similar levels of the KA receptor subtype 6 (Glu6/7) between $B m f^{+/+}$and $B m f^{-/-}$mice. $\beta$-Actin is shown as loading control ( $n=3$ per group). (e) Realtime qPCR analysis confirming absence of bmf mRNA was detected in $B m f^{-/-}$mice ( $n=4$ per group). (f) Graph and representative EEG traces showing similar amount of HAHFDs during SE induced by intra-amygdala KA between $B m f^{+/+}$and $B m f^{-/-}$mice recorded by Grass Comet digital EEG ( $n=10$ per group). (g-i) Graphs showing similar total power, amplitude and frequency between $\mathrm{Bmf}^{+/+}$and $\mathrm{Bmf}^{-/-}$mice during $\mathrm{SE}(n=10$ per group). (j) Representative seizure spectrogram showing amplitude and frequency during SE in $\mathrm{Bmf}^{+/+}$and $\mathrm{Bmf} \mathrm{f}^{-/-}$mice. (k) Graph and (I) representative seizure spectrogram showing amplitude and frequency for $1 \mathrm{~h}$ following lorazepam injection in $\mathrm{Bmf}^{+/+}$and $\mathrm{Bmf}^{-/-}$mice. ${ }^{* \star *} \mathrm{P}<0.001$ when compared with $\mathrm{Bmf}{ }^{+/+}$. Scale bar in a, $100 \mu \mathrm{m}$

visible in the hilus and CA1 region (Figures $5 a$ and b). In contrast, $\mathrm{Bmf}^{-/-}$mice showed significantly more hippocampal damage when compared with $\mathrm{Bmf}^{+/+}$littermates (Figures $5 \mathrm{a}$ and b). Cell death was not only increased in the cell death-susceptible CA3 region (Figures $5 \mathrm{c}$ and $\mathrm{d}$ ), but was also increased in the normally cell death-resistant subfield CA1 (Figures 5e and f). FJB-positive cells were also frequently present in the hilus and the contralateral hippocampus in $\mathrm{Bmf}{ }^{-/-}$mice (Figures $5 \mathrm{~g}$ and $\mathrm{h}$ ).

We previously reported neuroprotection during SE to exert an anti-epileptogenic effect in our model. ${ }^{8,35}$ To explore whether bmf-deficiency and the resulting increase in cell death has an impact on the emergent epileptic phenotype, $\mathrm{Bmf}^{+/+}$and $\mathrm{Bmf}^{-/-}$mice were video recorded continuously for 5 consecutive days 14 days after SE. $B m f^{-/}$mice experienced $\sim 30 \%$ more spontaneous seizures when compared with $\mathrm{Bmf}^{+/+}$mice (Supplementary Table 1).

\section{Discussion}

In the present study, we report for the first time that the $\mathrm{BH} 3-$ only protein Bmf is upregulated after SE and in epilepsy. 
a

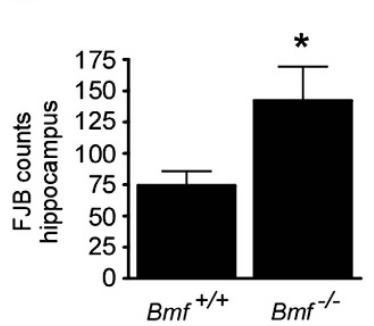

b

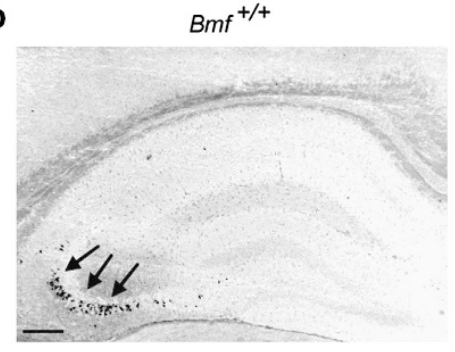

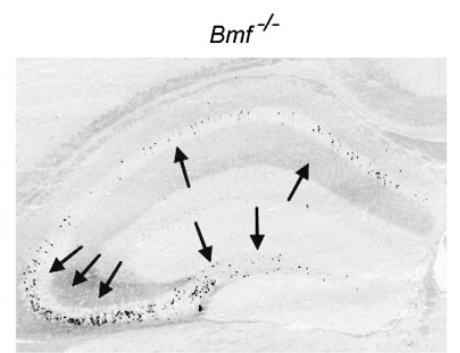

C
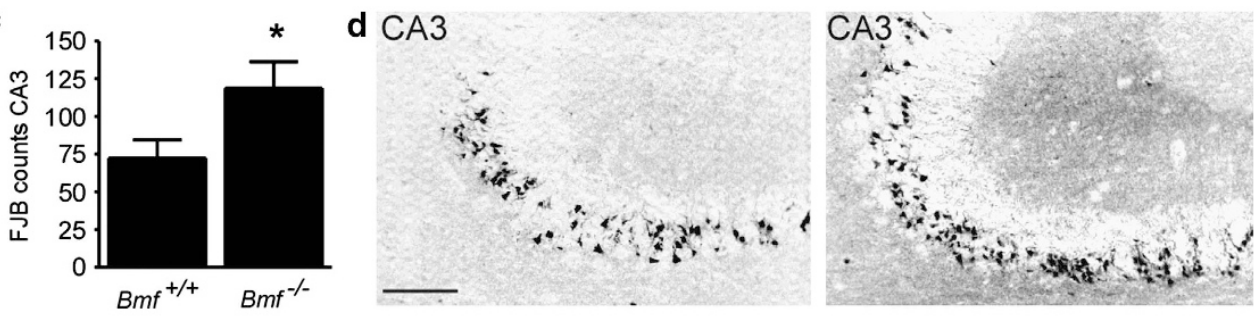

e
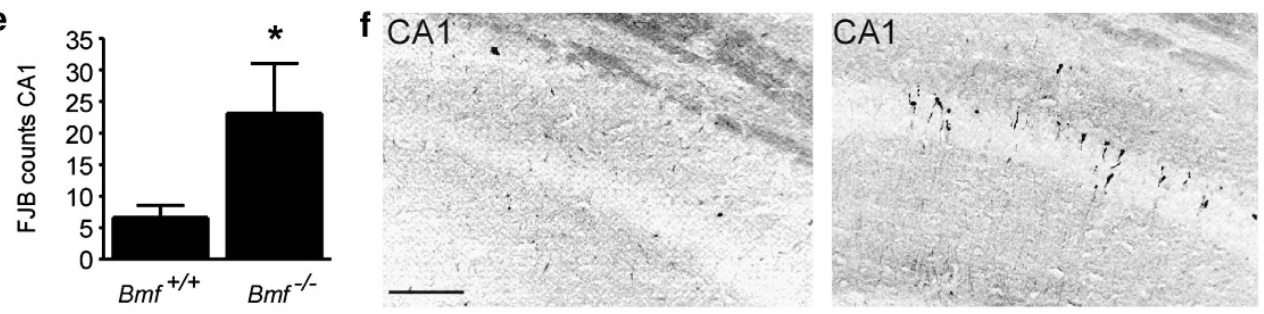

g
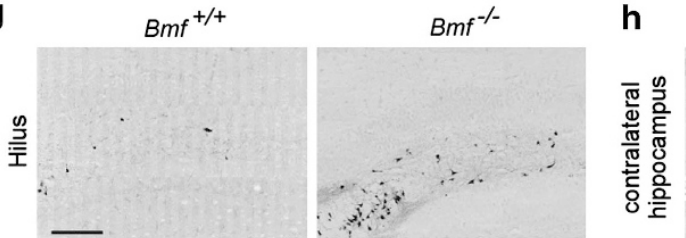

$\mathrm{Bmf}^{+/+}$

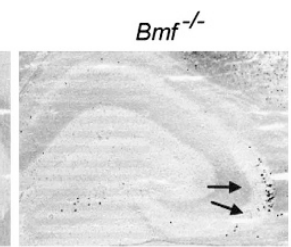

Figure 5 Increased vulnerability to seizure-induced neuronal death in $\mathrm{Bmf}^{-/-}$mice. (a) Graph and (b) representative field view photomicrograph showing more FJB-positive cells in the ipsilateral hippocampus $72 \mathrm{~h}$ after SE in Bmf ${ }^{-/-}$mice when compared with $B m f^{+/+}$mice $(n=10$ per group). Arrows mark areas of cell death. (c-f) Graph and representative photomicrographs showing increased FJB-positive cells in ipsilateral hippocampal subfields CA3 and CA1 in $B m f^{-/-}$mice when compared with $B m f^{+/+}$mice ( $n=10$ per group). ( $\mathbf{g}$ and $\mathbf{h}$ ) Photomicrographs showing presence of increased cell death in ipsilateral hilus $(P=0.18)$ and contralateral hippocampus $(P=0.18) 72 \mathrm{~h}$ after SE $(n=10) .{ }^{*} P<0.05$ when compared with $B m f^{+/+}$. Scale bar, $250 \mu \mathrm{m}(\mathbf{b}, \mathbf{h})$ and $150 \mu \mathrm{m}(\mathbf{d}, \mathbf{f}$ and $\mathbf{g})$

This was blocked by an inhibitor of AMPK implying this may be driven by seizure-induced ATP depletion. Critically, and in contrast to the established proapoptotic function of Bmf in non-neuronal tissue, we show that seizure-induced neuronal death is increased in the absence of the bmf gene. These are the first studies to explore Bmf regulation in a model of neurological disease, and suggest Bmf may be required to protect the brain against the harmful effects of seizures.

BH3-only proteins have emerged as novel regulators of seizure-induced cell death. ${ }^{3}$ Among the BH3-only proteins profiled to date, activation of several occurs in the hippocampus after SE, but only Puma and Bim appear to be causally involved in cell death. The most neuroprotection was observed when Puma was deleted. ${ }^{8,36}$ Loss of Bim resulted in protection in one study ${ }^{9}$, but failed to protect in another $\mathrm{KA}$ mode ${ }^{37}$, and Bid knockout mice showed similar damage as wild type mice after SE. ${ }^{38}$ This underscores the importance of elucidating the functional contribution of novel BH3-only proteins with the most pronounced effects. ${ }^{3}$ Here, we examined the novel BH3-only protein Bmf. A strength of the present study is that we have used the same SE model as was employed in the work on Puma, Bim and Bid, ensuring we can directly compare results to previous findings. The present study showed that SE results in increased expression of bmf in the hippocampus, expanding further the list of BH3-only proteins activated by seizures. This also increases the already considerable experimental and human evidence that seizures activate apoptosis-associated pathways in the brain.

Induction of bmf was rapid following seizures, in the same timeframe as Bax activation in the CA3 subfield at mitochondria. Whether Bax is required for seizure-induced neuronal death could not be established, because of the abnormalities of $\mathrm{Bax}^{-/-}$brains. Studying the functional role of Bax during SE will likely require conditional deletion of bax, to exclude effects on seizures or results being obscured by differences in cell densities. Regardless, these data are consistent with Bmf fulfilling an apical role in the signaling pathways induced by SE in the mouse hippocampus. 
A number of pathways have been identified that control $\mathrm{BH} 3-$ only protein induction after SE, including $\mathrm{p} 53,{ }^{8} \mathrm{Foxo},{ }^{39}$ JNK $^{9}$ and caspases. ${ }^{40}$ Bmf upregulation has previously been reported after various stimuli, including anoikis, UV radiation and AMPK activation. ${ }^{11}$ Here, we found that the AMPK inhibitor Compound $\mathrm{C}$ prevented bmf upregulation after SE, whereas a JNK inhibitor had no effect, suggesting bmf gene expression is mainly regulated through the AMPK pathway. This is consistent with a recently identified mechanism of Bmf induction in non-neuronal cells. ${ }^{15}$ AMPK inhibition did not decrease basal levels of bmf expression, suggesting other transcription factors being responsible to maintain normal physiological bmf levels. Another potential mechanism of AMPK activation, through CaMKK, ${ }^{41}$ is unlikely as seizures are known to decrease function of this enzyme. ${ }^{42}$ This is the first BH3-only protein to be linked to an energy-sensing pathway in the setting of seizures. Seizure activity can lead to energy depletion in affected brain regions. ${ }^{43,44}$ This results in activation of the bioenergetic cell stress sensor AMPK ${ }^{45,46}$, which suppresses key enzymes involved in ATP-consuming anabolic pathways and increases cellular ATP supply. ${ }^{47}$ Interestingly, activation of AMPK and $\mathrm{BH} 3-$ only proteins has both been linked to the induction of autophagy, 6,48 which has been reported to be protective during seizure-induced cell death. ${ }^{49}$ However, protein levels of autophagy-regulated proteins did not differ between $\mathrm{Bmf}^{+/+}$and $\mathrm{Bmf}^{-/_{-}}$mice after SE (TE, unpublished data). We cannot rule out that other, possibly post-translational modifications occur to Bmf. Indeed, previous work has shown Bmf to undergo phosphorylation by $\mathrm{JNK},{ }^{17}$ an enzyme activated by seizures in the present model. ${ }^{9}$ Other Bmf isoforms also exist, which have been reported to have different functions. ${ }^{12,13}$

Bmf was induced both acutely, after SE, and also in experimental epilepsy. This was unlikely to be due to active neurodegeneration, which is largely undetectable by 14 days post SE (presented data $a^{2} d^{28}$ ). Rather, spontaneous seizures may trigger bmf levels to increase in the mouse hippocampus. We do not know which of the hippocampal subfields contributes to bmf induction during chronic epilepsy. It may be the damaged CA3 subfield, which is only partly lesioned by SE and which has been shown to be the source of spontaneous seizure generation in this model, ${ }^{50}$ but contributions from other subfields are also possible. These are the first data to look at $\mathrm{BH} 3-o n l y$ protein induction in epileptic mice in this model, and suggest that both spontaneous and induced seizures upregulate the expression of Bmf.

The second major finding in the present study was that, unexpectedly, seizure-induced neuronal death was increased in mice lacking bmf. This increase was not restricted to the ipsilateral CA3 subfield alone, with increased damage extending into the CA1 also, an area normally relatively resistant to cell death in this model. ${ }^{28} \mathrm{We}$ also saw a trend to increased damage in the hilus and in the contralateral side of the bmf-deficient mouse hippocampus. Surface EEG recordings suggested mice underwent similar seizures. The present data implies, therefore, that Bmf protects the hippocampus against seizure-induced neuronal death in vivo. Our Compound $\mathrm{C}$ data are also consistent with a protective role of $\mathrm{BMF}$, as Compound $\mathrm{C}$ blocked the expression of bmf and increased seizure-induced cell death. The present finding of higher spontaneous seizure frequency in $\mathrm{Bmf}^{-/-}$mice is also consistent with previous findings in this model, where larger CA3 lesions were associated with more frequent epileptic seizures. ${ }^{51}$ These data contrast with previous studies of $\mathrm{BH} 3-$ only proteins in the same model that showed proapoptotic or redundant roles. ${ }^{3}$ Thus, Bmf represents the first BH3-only protein to be shown to have an anti-apoptotic function during seizure-induced neuronal death in vivo.

The present study is the first to examine seizure-induced neuronal death in vivo in mice lacking one of the weaker $\mathrm{BH} 3-$ only proteins. Bim, Puma or Bid are essential to activate the mitochondrial apoptotic pathway, but the weaker BH3-only proteins are now thought not essential to promote apoptosis. ${ }^{52}$ The results of the present study suggest Bmf not only does not promote apoptosis after seizures but, instead, serves an anti-apoptotic role. Bmf does not, therefore, perform the same functions in the brain that have been ascribed in other tissues. ${ }^{10,11}$ The brain is largely postmitotic, and proteins may well be co-opted to serve other functions which, when lost, disrupt neurophysiology and increase vulnerability to cell death. Although this is the first BH3-only protein to be assigned an anti-apoptotic role in the brain, loss of Bak, an otherwise proapoptotic protein, also increased seizure-induced neuronal death. ${ }^{53}$ Non-apoptotic roles have also been described for other Bcl-2 proteins in the brain, with Bad and Bax implicated in synaptic plasticity, including longterm depression. ${ }^{53,54} \mathrm{Bmf}$-deficient animals showed the same response to intra-amygdala $\mathrm{KA}$, suggesting that Bmf probably does not influence basal neurotransmission or excitability of neurons. One possible limitation of the present work is the use of cortical EEG, but previous work shows that there is a strong correlation between cortical seizures with hippocampal seizures and damage in our model. ${ }^{9,55}$ Elucidating the constitutive function of $\mathrm{Bmf}$ in the brain may provide insight into why loss of Bmf enhances injury after prolonged seizures. It is tempting to speculate a link exists with cell energy, and other BH3-only proteins have been linked to cell metabolism. ${ }^{56}$ Indeed, a recent study has shown that AMPK inhibition can lead to increased cell death by downregulating target genes that normally downregulate oxidative stress. ${ }^{46}$

In conclusion, the present study demonstrates that prolonged and single seizures in vivo activate the $\mathrm{BH}$-only protein Bmf. Induction of Bmf, at least following SE, may involve the AMPK pathway. Contrary to expectations, Bmf-deficiency increased seizure-induced neuronal death, suggesting Bmf may protect against the harmful effects of prolonged or repeated seizures in vivo. These data further demonstrate the functional influence of some Bcl-2 family proteins during seizure-induced neuronal death and importantly, to potentially novel roles for $\mathrm{BH} 3-o n l y$ proteins that may influence future approaches to neuroprotection and, possibly, anti-epileptogenesis.

\section{Materials and Methods}

Animal seizure model. All animal procedures were performed in accordance with the principles of the European Communities Council Directive (86/609/EEC) and the National Institutes of Health's Guide for the Care and Use of Laboratory Animals. Procedures were reviewed and approved by the Research Ethics Committee of the Royal College of Surgeons in Ireland, under license from the Department of Health, Dublin, Ireland. Studies were performed according to previously described techniques. ${ }^{57}$ Adult male mice (20-25 g) (C57BL/6 (Harlan, UK), Bmf $f^{+/+}$and $\mathrm{Bmf}^{-/-}\left(^{10}\right)$ and $\mathrm{Bax}^{+/+}$and $\mathrm{Bax}^{-/-}$mice 
(Jackson Laboratory, Bar Harbor, ME, USA (strain B6.129 $\times 1-B a x^{t m 1 S j k / J))}$ underwent seizures induced by unilateral sterotaxic microinjection of KA Ocean Produce International (Shelburne, NS, Canada) into the basolateral amygdala nucleus. Briefly, mice were anesthetized using isoflurane (3-5\%) and maintained normothermic by means of a feedback-controlled heat blanket (Harvard Apparatus Ltd, Kent, England). Next, mice were placed in a stereotaxic frame and following a midline scalp incision, three partial craniotomies were performed. Mice were affixed with three skull-mounted recording electrodes (Bilaney Consultants Ltd, Sevenoaks, Kent, UK) to record surface EEG. Electrodes were placed above the dorsal hippocampus and a third over the frontal cortex. EEG was recorded using a Grass Comet digital EEG (Medivent Ltd, Lucan, Ireland). A guide cannula was affixed over the dura (co-ordinates from Bregma: A $P=-0.94 ; L=-2.85 \mathrm{~mm}$ ) and the entire skull assembly fixed in place with dental cement. Anesthesia was discontinued, EEG recordings were commenced, and then a 31-gauge internal cannula (Plastic One Inc., Roanoke, VI, USA) was inserted into the lumen of the guide to inject KA $(0.3 \mu \mathrm{g}$ in $0.2 \mu \mathrm{l}$ of vehicle; phosphate-buffered saline (PBS), $\mathrm{pH}$ adjusted to 7.4 ) into the amygdala. Non-seizure control animals received the same volume of intra-amygdala vehicle. EEG was recorded until intra-peritoneal lorazepam $(6 \mathrm{mg} / \mathrm{kg})$ administration at $40 \mathrm{~min}$. Mice were euthanized after $1,4,8$, $24,72 \mathrm{~h}$ and 14 days after anticonvulsant, and brains were microdissected on ice and processed for protein analysis, as described below, or flash-frozen whole in 2 methylbutane at $-30^{\circ} \mathrm{C}$ for immunohistochemistry as previously described. ${ }^{57}$ Brains from additional naive (non-instrumented) $\mathrm{Bmf}^{+/+}$and $\mathrm{Bmf}^{-/-}$mice were used to examine hippocampal neuroanatomy and basal gene expression. To examine the brain abnormalities in $\mathrm{Bax}^{-1-}$ mice, male $\mathrm{Bax}^{+/+}$and $\mathrm{Bax}^{-1-}$ mice of same age were saline perfused, extracted and weighed on a scale.

Quantification of EEG. Digitized EEG recordings were analyzed off-line using manual assessment and automated software as described. ${ }^{57}$ The duration of highfrequency $(>5 \mathrm{~Hz})$ and high-amplitude ( $>2 \mathrm{X}$ baseline) polyspike discharges of $\geq 5 \mathrm{~s}$ duration (HAHFDs), which are synonymous with injury-causing electrographic activity, was counted by a reviewer blind to the treatment. Further EEG analysis was performed by uploading EEG into Labchart7 software (ADInstruments, Oxford, UK) to calculate total power, amplitude and frequency of the EEG signal.

Analysis of spontaneous seizures using EEG telemetry. Longterm EEG recording to define the emergence of epilepsy in wild-type mice was performed using implantable EEG telemetry units (Data Sciences International (DSI), St. Paul, MN, USA), as described previously. ${ }^{32}$ Mice underwent the same initial surgical procedure for affixing the injection cannula, but were equipped with EEG transmitters (F20-EET, DSI) to record bilateral EEG from skull screws overlying the dorsal ipsilateral and contralateral hippocampi. EEG data were acquired using the Dataquest A.R.T. system (DSI). Following surgery, mice received intra-amygdala $K A$, and then telemetry units were activated. Epileptic seizures were defined as high-frequency $(>5 \mathrm{~Hz})$ high-amplitude $(>2 \times$ baseline) polyspike discharges of $\geq 5 \mathrm{~s}$ duration.

\section{Analysis of behavioral changes during SE and spontaneous seizures by continuous video monitoring. $B m f^{+/+}$and $B m f^{-1-}$} mice were subjected to intra-amygdala KA-induced SE as described above, and epileptic seizure frequency determined as previously published. ${ }^{30}$ Mice were either monitored during 40 min after KA injection or allowed to recover after SE, and were then housed in pairs in clear Perspex cages. Webcam-style cameras connected to laptop computers were placed $40 \mathrm{~cm}$ from the cages in a room equipped with safe lights for night-time recordings. Images were captured using VirtualDub 1.9.11 (SourceForge.net) with a sampling rate of 10 frames per second and a data transfer rate of $140 \mathrm{~kb} / \mathrm{s}$. Videos from first $40 \mathrm{~min}$ after KA injection until lorazepam treatment or from 5 days of continuous monitoring were reviewed by an observer unaware of the experimental treatment. Seizures were counted using a modified six-point Racine scale for mice. The scores were determined as follows: (1) immobility and sudden freezing; (2) forelimb and or tail extension, rigid posture; (3) repetitive movements, head bobbing; (4) rearing and falling; (5) continuous rearing and falling; or (6) severe tonic-clonic seizures. For spontaneous seizure scoring clinical events scoring below 2 such as sudden freezing and immobility were not included.

Compound $\mathbf{C}$ and JNK inhibitor treatment. Mice received a $2 \mu \mathrm{l}$ i.c.v. injection of the JNK inhibitor SP600125 $(25 \mu \mathrm{M})$ in DMSO ${ }^{9} 4 \mathrm{~h}$ before intra-amygdala KA. Vehicle mice received DMSO alone. For AMPK inhibition, mice received a $2 \mu \mathrm{l}$ i.c.v. injection of Compound C (1 mM) in DMSO $4 \mathrm{~h}$ before SE.
Western blotting. Western blotting was performed as previously described. ${ }^{38}$ Whole hippocampi or CA3 subfields were homogenized in lysis buffer and protein concentration was determined. Fifty microgram protein samples were boiled in gelloading buffer and separated on 10 to $15 \%$ SDS-PAGE gels. Proteins were transferred onto nitrocellulose membranes (Bio-Rad, Hercules, CA, USA) and then incubated with antibodies against the following: Full-length Bax (Upstate Biotechnologies, Millipore Ireland BV, Cork, Ireland), AMPK and AMPK-P (Cell Signaling Technology, Danvers, MA, USA), Glu6/7 (Chemicon, Hampshire, UK), KA2 (Merck Millipore, Cork, Ireland), BMF (N-terminal from Prosci, Poway, CA, USA; internal region of BMF protein, Santa Cruz, Germany, Heidelberg), $\beta$-Actin (Sigma-Aldrich, Dublin, Ireland) and $\alpha$-Tubulin (Santa Cruz Biotechnology, Heidelberg, Germany). Membranes were then incubated with horseradish peroxidase-conjugated secondary antibodies (Jackson ImmunoResearch, Plymouth, PA, USA) and bands visualized using Supersignal West Pico Chemiluminescent Substrate (Pierce, Rockford, IL, USA). Images were captured using a Fuji-film LAS-300, densitometry performed using AlphaEaseFC4.0 software, and data expressed as change relative to control.

RNA extraction and real time-quantitative PCR. RNA extraction was undertaken as previously described using Trizol (Invitrogen). ${ }^{35}$ Briefly, one microgram total RNA was used to generate CDNA by reverse transcription using Superscript II Reverse Transcriptase enzyme (Invitrogen, Dublin, Ireland). Quantitative real-time PCR was performed using a LightCycler 1.5 (Roche Diagnostics, Sussex, UK) in combination with QuantiTech SYBR Green PCR kit (Qiagen Ltd, Crawley, UK) as per manufacturer's protocol and $1.25 \mu \mathrm{M}$ of primer pair used. Data were analyzed by LightCycler 1.5 software, data normalized to expression of $\beta$-actin and represented at $R Q$ values. Primers were designed using Primer3 software (http://frodo.wi.mit.edu) and verified by BLAST (http://blast.ncbi.nlm.nih.gov/Blast.cgi). Primers sequences: Arc: forward-5'-TGACTCACAACTGCCACACA3-3', reverse-5'-ATGAGGAAGCCAGATCGTGT-3'; Puma: forward-5'-TCTCAGGAAAGGCTGCTGGT-3', reverse-5'-GCTGGGCACTGGGTTAAGAA-3'; Bim: forward-5'-CAACACAAACCCCAAGTCCT-3', reverse-5'-CAT TTGCAAACACCCTCCTT-3'; Bmf. forward-5'-CCCATAAGCCAGGAAGACAA-3', reverse-5'-CTGAAGCTTTCTGGCGATTCT-3'; Bax: forward-5'-AACCATCATGG GCTGGACAC-3', reverse-5'-GAGGCCTCAGCCCATCTTCT-3'.

Confocal microscopy. For confocal microscopy, animals were transcardially perfused with 4\% PFA, brains were removed and post-fixed for 1 day, and then cut on a vibratome (INTRACEL, Royston, UK) in $30 \mu \mathrm{m}$ thick sections. Sections were washed in PBS and permeabilized with $0.2 \%$ CHAPS/PBS for $5 \mathrm{~min}$. Following permeabilization, slides were blocked for $1 \mathrm{~h}$ in PBS/1\% bovine serum albumin $/ 3 \%$ serum. Bax conformational change was detected with the antiBax 6A7. Primary antibody was diluted 1:500 in blocking buffer and was added and incubated overnight at $4{ }^{\circ} \mathrm{C}$. Sections were washed three times with PBS, and incubated with a 1:250 dilution of FITC-conjugated goat anti-mouse secondary antibody (Jackson Immuno Research Europe, Suffolk, UK) for $2 \mathrm{~h}$ at room temperature. Next, sections were incubated for 10 min with DAPI at RT, washed in PBS and coverslipped with Fluorosave. Confocal images were acquired with a Leica TCR 6500 microscope equipped with four laser lines (405, 488, 561 and $653 \mathrm{~nm}$ ) using a $63 \mathrm{X}$ immersion oil objective (NA 1.3).

Histopathology. Fresh-frozen coronal brain sections at the level of the dorsal hippocampus were air-dried, fixed in formalin and stained with antibodies against NeuN (Chemicon, Hampshire, UK) and detected by goat anti-mouse AlexaFluor 568 (Bio Sciences, Dublin, Ireland). Neuronal damage was assessed by Fluoro-Jade B staining (FJB) (Millipore, Cork, Ireland). ${ }^{57}$ Sections were imaged using a Nikon 2000s epifluorescence microscope with a Hamamatsu Orca 285 camera (Micron-Optical, Wexford, Ireland). Semi-quantification of damaged and/or surviving cells was performed for the entire CA3 subfield, beginning at the border with $\mathrm{CA} 2$ through to the end of CA3c/CA4 within the hilus of the dentate gyrus and for the entire CA1 subfield beginning at border with CA2 through to the end of CA1. Counts were the average of two adjacent sections assessed by an observer masked to experimental group/condition. For investigation of the brain architecture in wild-type and $\mathrm{Bmf}^{-1-}$ mice, naive brains were also prepared. Sections were prepared and immunostained for NeuN.

Data analysis. Data are presented as means \pm S.E. Data were analyzed using ANOVA with post-hoc Fisher's PLSD test, Student's $t$-test for two-group 
comparison and Mann-Whitney test for non-parametric data (StatView software; SAS Institute, Cary, NC, USA). Significance was accepted at $P<0.05$.

\section{Conflict of Interest}

The authors declare no conflict of interest.

Acknowledgements. This work was supported by funding from the Health Research Board (PD/2009/31 to TE and HRA_POR/2011/41 to DCH) and by Science Foundation Ireland (08/IN.1./B1875 to DCH) and (08/IN.1/B1949 to JHP). We thank Dr. Andreas Villunger (Division of Developmental Immunology, Biocenter, Innsbruck Medical University, Innsbruck, Austria) and Dr. Andreas Strasser (Department of Medical Biology, Melbourne University, Melbourne, Victoria, Australia) for providing the Bmf knockout mice.

1. Henshall DC, Simon RP. Epilepsy and apoptosis pathways. J Cereb Blood Flow Metab 2005; 25: 1557-1572.

2. Pitkanen A, Sutula TP. Is epilepsy a progressive disorder? Prospects for new therapeutic approaches in temporal-lobe epilepsy. Lancet Neurol 2002; 1: 173-181.

3. Engel T, Plesnila N, Prehn JH, Henshall DC. In vivo contributions of $\mathrm{BH}$-only proteins to neuronal death following seizures, ischemia, and traumatic brain injury. J Cereb Blood Flow Metab 2011; 31: 1196-1210.

4. Engel T, Henshall DC. Apoptosis, Bcl-2 family proteins and caspases: the ABCs of seizuredamage and epileptogenesis? Int J Physiol Pathophysiol Pharmacol 2009; 1: 97-115.

5. Bouillet $\mathrm{P}$, Strasser A. BH3-only proteins - evolutionarily conserved proapoptotic Bcl-2 family members essential for initiating programmed cell death. J Cell Sci 2002; 115(Pt 8): 1567-1574.

6. Shamas-Din A, Brahmbhatt H, Leber B, Andrews DW. BH3-only proteins: Orchestrators of apoptosis. Biochim Biophys Acta 2011; 1813: 508-520.

7. Puthalakath $\mathrm{H}$, Strasser A. Keeping killers on a tight leash: transcriptional and posttranslational control of the pro-apoptotic activity of $\mathrm{BH} 3$-only proteins. Cell Death Differ 2002; 9: 505-512.

8. Engel T, Murphy BM, Hatazaki S, Jimenez-Mateos EM, Concannon CG, Woods I et al. Reduced hippocampal damage and epileptic seizures after status epilepticus in mice lacking proapoptotic Puma. FASEB J 2010; 24: 853-861.

9. Murphy BM, Engel T, Paucard A, Hatazaki S, Mouri G, Tanaka K et al. Contrasting patterns of Bim induction and neuroprotection in Bim-deficient mice between hippocampus and neocortex after status epilepticus. Cell Death Differ 2010; 17: 459-468.

10. Puthalakath H, Villunger A, O'Reilly LA, Beaumont JG, Coultas L, Cheney RE et al. Bmf: a proapoptotic $\mathrm{BH} 3$-only protein regulated by interaction with the myosin $\mathrm{V}$ actin motor complex, activated by anoikis. Science 2001; 293: 1829-1832.

11. Pinon JD, Labi V, Egle A, Villunger A. Bim and Bmf in tissue homeostasis and malignant disease. Oncogene 2008; 27(Suppl 1): S41-S52.

12. Morales AA, Olsson A, Celsing F, Osterborg A, Jondal M, Osorio LM. Expression and transcriptional regulation of functionally distinct Bmf isoforms in B-chronic lymphocytic leukemia cells. Leukemia 2004; 18: 41-47.

13. Grespi F, Soratroi C, Krumschnabel G, Sohm B, Ploner C, Geley S et al. BH3-only protein Bmf mediates apoptosis upon inhibition of CAP-dependent protein synthesis. Cell Death Differ 2010; 17: 1672-1683.

14. Ramjaun AR, Tomlinson S, Eddaoudi A, Downward J. Upregulation of two BH3-only proteins, Bmf and Bim, during TGF beta-induced apoptosis. Oncogene 2007; 26: 970-981.

15. Kilbride SM, Farrelly AM, Bonner C, Ward MW, Nyhan KC, Concannon CG et al. AMP-activated protein kinase mediates apoptosis in response to bioenergetic stress through activation of the pro-apoptotic Bcl-2 homology domain-3-only protein BMF. J Biol Chem 2010; 285: 36199-36206.

16. Zhang $\mathrm{Y}$, Adachi M, Kawamura R, Imai K. Bmf is a possible mediator in histone deacetylase inhibitors FK228 and CBHA-induced apoptosis. Cell Death Differ 2006; 13: $129-140$.

17. Tianhu Z, Shiguang Z, Xinghan L. Bmf is upregulated by PS-341-mediated cell death of glioma cells through JNK phosphorylation. Mol Biol Rep 2010; 37: 1211-1219.

18. Schmelzle T, Mailleux AA, Overholtzer M, Carroll JS, Solimini NL, Lightcap ES et al. Functional role and oncogene-regulated expression of the BH3-only factor Bmf in mammary epithelial anoikis and morphogenesis. Proc Natl Acad Sci USA 2007; 104: 3787-3792.

19. Kuwana T, Bouchier-Hayes L, Chipuk JE, Bonzon C, Sullivan BA, Green DR et al. BH3 domains of $\mathrm{BH} 3$-only proteins differentially regulate Bax-mediated mitochondrial membrane permeabilization both directly and indirectly. Mol Cell 2005; 17: 525-535.

20. Du H, Wolf J, Schafer B, Moldoveanu T, Chipuk JE, Kuwana T. BH3 domains other than Bim and Bid can directly activate Bax/Bak. J Biol Chem 2011; 286: 491-501.

21. Labi V, Erlacher M, Kiessling S, ManzI C, Frenzel A, O'Reilly L et al. Loss of the BH3-only protein Bmf impairs $B$ cell homeostasis and accelerates gamma irradiation-induced thymic lymphoma development. J Exp Med 2008; 205: 641-655.
22. Hausmann M, Leucht $\mathrm{K}$, Ploner $\mathrm{C}$, Kiessling S, Villunger A, Becker $\mathrm{H}$ et al. BCL-2 modifying factor (BMF) is a central regulator of anoikis in human intestinal epithelial cells. $J$ Biol Chem 2011; 286: 26533-26540.

23. Morales AA, Gutman D, Lee KP, Boise LH. BH3-only proteins Noxa, Bmf, and Bim are necessary for arsenic trioxide-induced cell death in myeloma. Blood 2008; 111: 5152-5162.

24. Lau GJ, Godin N, Maachi H, Lo CS, Wu SJ, Zhu JX et al. Bcl-2-modifying factor induces renal proximal tubular cell apoptosis in diabetic mice. Diabetes 2012; 61: 474-484.

25. Hubner A, Cavanagh-Kyros J, Rincon M, Flavell RA, Davis RJ. Functional cooperation of the proapoptotic Bcl2 family proteins Bmf and Bim in vivo. Mol Cell Biol 2010; 30: 98-105.

26. Baumgartner F, Woess C, Pedit V, Tzankov A, Labi V, Villunger A. Minor cell-death defects but reduced tumor latency in mice lacking the BH3-only proteins Bad and Bmf. Oncogene 2012; 32: 621-630.

27. Araki T, Simon RP, Taki W, Lan JQ, Henshall DC. Characterization of neuronal death induced by focally evoked limbic seizures in the C57BL/6 mouse. J Neurosci Res 2002; 69: 614-621.

28. Mouri G, Jimenez-Mateos E, Engel T, Dunleavy M, Hatazaki S, Paucard A et al. Unilateral hippocampal CA3-predominant damage and short latency epileptogenesis after intraamygdala microinjection of kainic acid in mice. Brain Res 2008; 1213: 140-151.

29. Shao Y, Aplin AE. BH3-only protein silencing contributes to acquired resistance to PLX4720 in human melanoma. Cell Death Differ 2012; 19: 2029-2039.

30. Jimenez-Mateos EM, Engel T, Merino-Serrais P, McKiernan RC, Tanaka K, Mouri G et al. Silencing microRNA-134 produces neuroprotective and prolonged seizure-suppressive effects. Nat Med 2012; 18: 1087-1094.

31. Hardie DG, Ross FA, Hawley SA. AMPK: a nutrient and energy sensor that maintains energy homeostasis. Nat Rev Mol Cell Biol 2012; 13: 251-262.

32. Engel T, Tanaka K, Jimenez-Mateos EM, Caballero-Caballero A, Prehn JH, Henshall DC. Loss of p53 results in protracted electrographic seizures and development of an aggravated epileptic phenotype following status epilepticus. Cell Death Dis 2010; 1: e79.

33. Shimizu S, Simon RP, Graham SH. Dimethylsulfoxide (DMSO) treatment reduces infarction volume after permanent focal cerebral ischemia in rats. Neurosci Lett 1997; 239: 125-127.

34. Steward O, Wallace CS, Lyford GL, Worley PF. Synaptic activation causes the mRNA for the IEG Arc to localize selectively near activated postsynaptic sites on dendrites. Neuron 1998; 21: 741-751.

35. Jimenez-Mateos EM, Hatazaki S, Johnson MB, Bellver-Estelles C, Mouri G, Bonner C et al. Hippocampal transcriptome after status epilepticus in mice rendered seizure damagetolerant by epileptic preconditioning features suppressed calcium and neuronal excitability pathways. Neurobiol Dis 2008; 32: 442-453.

36. Engel T, Hatazaki S, Tanaka K, Prehn JH, Henshall DC. Deletion of Puma protects hippocampal neurons in a model of severe status epilepticus. Neuroscience 2010; 168: 443-450.

37. Theofilas $P$, Bedner $P$, Huttmann $K$, Theis M, Steinhauser C, Frank S. The proapoptotic BCL-2 homology domain 3-only protein Bim is not critical for acute excitotoxic cell death. $J$ Neuropathol Exp Neurol 2009; 68: 102-110.

38. Engel T, Caballero-Caballero A, Schindler CK, Plesnila N, Strasser A, Prehn JH et al. $\mathrm{BH} 3-$ only protein Bid is dispensable for seizure-induced neuronal death and the associated nuclear accumulation of apoptosis-inducing factor. J Neurochem 2010; 115: 92-101.

39. Shinoda S, Schindler CK, Meller R, So NK, Araki T, Yamamoto A et al. Bim regulation may determine hippocampal vulnerability after injurious seizures and in temporal lobe epilepsy. J Clin Invest 2004; 113: 1059-1068.

40. Henshall DC, Bonislawski DP, Skradski SL, Lan JQ, Meller R, Simon RP. Cleavage of bid may amplify caspase-8-induced neuronal death following focally evoked limbic seizures. Neurobiol Dis 2001; 8: 568-580.

41. Hawley SA, Pan DA, Mustard KJ, Ross L, Bain J, Edelman AM et al. Calmodulindependent protein kinase kinase-beta is an alternative upstream kinase for AMP-activated protein kinase. Cell Metab 2005; 2: 9-19.

42. Bronstein J, Farber D, Wasterlain C. Decreased calmodulin kinase activity after status epilepticus. Neurochem Res 1988; 13: 83-86.

43. Fujikawa DG, Vannucci RC, Dwyer BE, Wasterlain CG. Generalized seizures deplete brain energy reserves in normoxemic newborn monkeys. Brain Res 1988; 454: 51-59.

44. Kovac S, Abramov AY, Walker MC. Energy depletion in seizures: Anaplerosis as a strategy for future therapies. Neuropharmacology 2012; 69: 96-104.

45. Lee JY, Jeon BT, Shin HJ, Lee DH, Han JY, Kim HJ et al. Temporal expression of AMP-activated protein kinase activation during the kainic acid-induced hippocampal cell death. J Neural Transm 2009; 116: 33-40.

46. Han Y, Xie N, Cao L, Zhao X, Liu X, Jiang H et al. Adenosine monophosphate-activated protein kinase and peroxisome proliferator-activated receptor gamma coactivator 1alpha signaling provides neuroprotection in status epilepticus in rats. Neurosci Lett 2011; 500: 133-138.

47. Kemp BE, Mitchelhill KI, Stapleton D, Michell BJ, Chen ZP, Witters LA. Dealing with energy demand: the AMP-activated protein kinase. Trends Biochem Sci 1999; 24: 22-25.

48. Mihaylova MM, Shaw RJ. The AMPK signalling pathway coordinates cell growth, autophagy and metabolism. Nat Cell Biol 2011; 13: 1016-1023.

49. Wong M. Mammalian target of rapamycin (mTOR) inhibition as a potential antiepileptogenic therapy: from tuberous sclerosis to common acquired epilepsies. Epilepsia 2010; 51: 27-36.

50. Li T, Ren G, Lusardi T, Wilz A, Lan JQ, Iwasato T et al. Adenosine kinase is a target for the prediction and prevention of epileptogenesis in mice. J Clin Invest 2008; 118: 571-582. 
51. Engel T, Sanz-Rodgriguez A, Jimenez-Mateos EM, Concannon C, Jimenez-Pacheco A, Moran $\mathrm{C}$ et al. $\mathrm{CHOP}$ regulates the p53-MDM2 axis and is required for neuronal survival after seizures. Brain 2012; 136(Pt 2): 577-592.

52. Ren D, Tu HC, Kim H, Wang GX, Bean GR, Takeuchi $\mathrm{O}$ et al. BID, BIM, and PUMA are essential for activation of the BAX-and BAK-dependent cell death program. Science 2010; 330: 1390-1393.

53. Fannjiang $\mathrm{Y}, \mathrm{Kim} \mathrm{CH}$, Huganir RL, Zou S, Lindsten $\mathrm{T}$, Thompson $\mathrm{CB}$ et al. BAK alters neuronal excitability and can switch from anti- to pro-death function during postnatal development. Dev Cell 2003; 4: 575-585.

54. Jiao S, Li Z. Nonapoptotic function of BAD and BAX in long-term depression of synaptic transmission. Neuron 2011; 70: 758-772.

55. Jimenez-Mateos EM, Bray I, Sanz-Rodriguez A, Engel T, McKiernan RC, Mouri G et al miRNA expression profile after status epilepticus and hippocampal neuroprotection by targeting miR-132. Am J Pathol 2011; 179: 2519-2532.
56. Deng H, Yu F, Chen J, Zhao Y, Xiang J, Lin A. Phosphorylation of Bad at Thr-201 by JNK1 promotes glycolysis through activation of phosphofructokinase-1. J Biol Chem 2008; 283: 20754-20760

57. Engel T, Gomez-Villafuertes R, Tanaka K, Mesuret G, Sanz-Rodriguez A, Garcia-Huerta P et al. Seizure suppression and neuroprotection by targeting the purinergic $\mathrm{P} 2 \mathrm{X} 7$ receptor during status epilepticus in mice. FASEB J 2012; 26: 1616-1628.

(c) (1) () (2) Cell Death and Disease is an open-access journal published by Nature Publishing Group. This work is licensed under a Creative Commons Attribution-NonCommercialShareAlike 3.0 Unported License. To view a copy of this license, visit http://creativecommons.org/licenses/by-nc-sa/3.0/

Supplementary Information accompanies this paper on Cell Death and Disease website (http://www.nature.com/cddis) 